\title{
Una sociología moral de las relaciones bancarias
}

\author{
Ariel Wilkis
}

JEANNE LAZARUS, 2012

L'épreuve de l'argent. Banques, banquiers, clients

Calman Lévy, París, 418 pp.

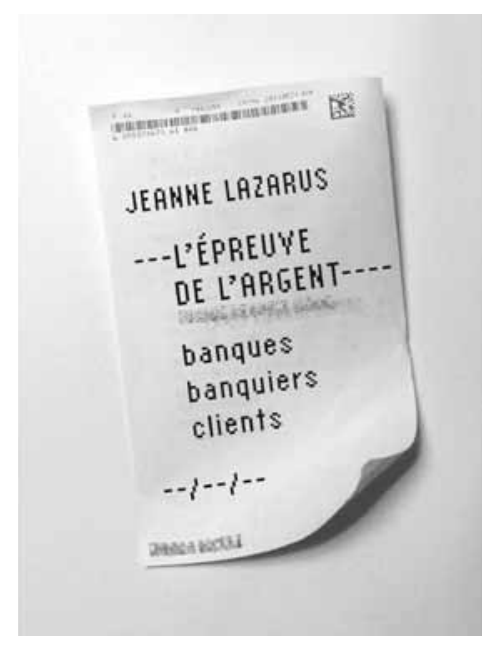

SOCIOLOGÍA DE LAS RELACIONES BANCARIAS

$\mathrm{E}$ n la última década se ha producido un creciente interés en la sociología, la antropología y la historia por el estudio de las finanzas. En Estados Unidos y Europa se han editado libros, organizado coloquios, publicado dossiers en revistas especializadas, creado grupos de investigación e incluso un área disciplinar específica

\section{A Moral Sociology of Banking Relationships}

ArIEL WiLKIs: Universidad Nacional de San Martín, Buenos Aires, Argentina ariel.wilkis@gmail.com

Desacatos, núm. 44, enero-abril 2014, pp. 210-215
- social studies of finance-. La crisis de las subprime en 2008 le ha dado un nuevo impulso a este tópico en la sociología económica (Carruthers y Kim, 2011). En nuestra región también hemos sido testigos - y partícipes- de la emergencia de una agenda de investigación centrada en interrogar las relaciones y prácticas financieras formales e informales, lícitas e ilícitas, tradicionales y nuevas (Villarreal, 2009; Müller, 2009; Wilkis, 2010; Ossandón, 2011). A riesgo de simplificar, podemos ver que la literatura especializada se ha organizado en los siguientes tópicos: el análisis de la sociohistoria de las instituciones, los instrumentos y los saberes financieros; el estudio de técnicas y tecnologías de evaluación 
crediticia; el estudio de los conocimientos económicos ordinarios y las estrategias económicas de los hogares en relación con una oferta extendida y diversificada de instrumentos financieros; el estudio de las finanzas alternativas (Maurer, 2012).

El trabajo de Jeanne Lazarus (2012) es una pieza clave en este ordenamiento del conocimiento de las ciencias sociales sobre las instituciones, las prácticas y los saberes centrales del capitalismo, cuyo rasgo dominante es la financiarización (Lapavitzas, 2009). La atención de la obra de Lazarus en el estudio de las relaciones bancarias tiene un objetivo claro: develar que estas relaciones no tienen nada de anodinas. Por el contrario, en torno a ellas pasan cosas, $y$ muchas. El trabajo de Lazarus pone de manifiesto la renovación de una sociología económica que coloca entre paréntesis al monocolor con el que suele pintarse el universo mercantil: impersonal, distante, frío, calculador. En palabras de Simmel, la sociología de L'épreuve de l'argent... está preocupada por la policromía de los lazos sociales, incluyo aquellos que a simple vista nos parecen grises. Lazarus sigue esta premisa y colorea las relaciones bancarias con los utensilios conceptuales de una sociología moral, cuyas fuentes se encuentran en los trabajos de Luc Boltanski y Laurent Thévenot.
Esta perspectiva marca la interpretación y las elecciones metodológicas. ¿Cómo analizar la relación entre los bancos y sus clientes? Para la autora, si los bancos son instituciones sociales ello obedece a que son espacios normativos donde se plasman clasificaciones y evaluaciones. Los bancos "esperan de sus clientes ciertas competencias, éstos aceptan pasar las pruebas y los juicios sobre ellos". El concepto de prueba indica qué se pone en juego en la relación bancaria: la evaluación de los bienes y las personas está en el corazón de la actividad cotidiana de los bancos, el vínculo entre empleados y clientes se teje por un constante trabajo de definición de lo que está permitido y lo que está prohibido. De aquí se desprende una hipótesis que requiere ser resuelta por una sociología moral de las relaciones bancarias. Las instituciones bancarias en Francia están atravesadas por una contradicción normativa.

Pensadas durante largo tiempo como un servicio público, desde la década de 1980 han devenido cada vez más un sector ultracompetitivo y rentable. Por tanto, los bancos oscilan entre ser instituciones sociales y espacios puramente comerciales.

Esta tensión recubre toda la relación entre los bancos y sus clientes, motivo por el cual la metodología de la investigación de Lazarus es saber qué pasa a ambos lados de las ventanillas: las lógicas de acción y los fundamentos morales de los empleados y los clientes que se despliegan alrededor de la prueba bancaria. Desde este punto de vista, L'épreuve... se centra en las interacciones entre empleados y clientes - sobre todo en comprender los mecanismos por medio de los cuales esta relación se prolonga en la vida cotidianay permite sacar a la luz cómo la banca penetra la economía doméstica, la intimidad y los afectos. Este libro propone una exploración en las relaciones bancarias que tiene como equipaje una densa cultura sociológica y el manejo de los debates de la sociología económica contemporánea. Las páginas que siguen tratarán de mapear el trayecto de esta exploración.

\section{PRUEBAS Y TENSIONES DE LA RELACIÓN BANCARIA}

La sociología de la relación bancaria que emprende Lazarus tiene un antecedente claro en uno de los trabajos menos conocidos de Pierre Bourdieu (Bourdieu, Boltanski y Chamboredon, 1963). Los hallazgos de Bourdieu y sus colegas nos hablan de las conductas económicas y las actitudes éticas requeridas por el incipiente crecimiento del sistema bancario. El trabajo de Lazarus se desarrolla 40 años después y con 
un paisaje social definido: al filo de la primera década del siglo Xxi, la bancarización de la sociedad francesa es un proceso consumado $-99 \%$ de los franceses posee una cuenta bancaria-. El capítulo 1 nos brinda indicios de la sociohistoria de esta expansión: la bancarización es un proceso impulsado por el Estado a través de legislaciones específicas orientadas a incorporar el dinero de los hogares a los flujos económicos nacionales. La banca francesa comienza una transformación marcada por su modernización y la expansión de instrumentos bancarios para los hogares. Este proceso es ayudado por la mensualización de los

212 ingresos de los trabajadores. Lazarus establece esta conexión claramente: la bancarización está ligada a la asalarización de la sociedad francesa. La apertura de la banca al gran público instala en el corazón de la relación entre los bancos y sus clientes la tensión normativa entre objetivos de un servicio público y los de una empresa comercial. Esta tensión se profundiza desde la década de 1980, cuando el sistema bancario se vuelve más competitivo y el perfil comercial es asumido. Los objetivos están orientados a rentabilizar a los clientes con la oferta de más servicios y productos. Los consejeros bancarios se encargan de recolectar información para las bases de datos y seguir procedimientos estándar de ofrecimientos de servicios y productos. El crédito cambia de estatus: es un producto a vender.

En el capítulo 2 la tensión normativa es analizada a partir de los intercambios que ocurren en las oficinas de los bancos entre empleados y clientes. Con base en la sociología dramatúrgica de Erving Goffman, Lazarus encuentra en sus observaciones cuatro figuras de empleados bancarios que expresan la tensión moral presente en estos intercambios: el comerciante, el juzgador, el consejero y el salvador permiten comprender la heterogeneidad de registros de interacción y evaluación de los mismos. Cada una de ellas remite a pruebas bancarias opuestas, como la posesión de bienes económicos - el comerciante-, el cumplimiento de reglas morales y jurídicas - el juzgador-, dedicar tiempo - el consejero- y la simpatía -el salvador-. Estas figuras están en tensión y coexisten, pueden incluso ser actuadas por un mismo empleado en diferentes circunstancias con un mismo cliente o con otro. $\mathrm{Al}$ describir estas figuras, Lazarus pone al descubierto una relación cambiante y compleja entre empleados y clientes, y refuta así una visión estática de lo que ocurre en la banca.

La autora del libro cita a Michel Callon (1986): “Traducir es decir en el propio lenguaje lo que otros dicen y quieren". Y con esta idea nos conduce, a lo largo del capítulo 3, a comprender que el intercambio bancario implica una operación de traducción que normativiza la relación entre empleados y clientes. El dinero está enmarañado - attachéa múltiples vínculos, contactos y relaciones. ¿Qué pasa con éstos cuando se entra en contacto con la banca? El empleado bancario debe traducir este enmarañamiento del dinero en los términos de los programas informáticos que hacen posible ofrecer un servicio a los clientes. La primera traducción es convertir lo que buscan los clientes en una de las propiedades distinguibles del nuevo espíritu del capitalismo (Boltanski y Chiapello, 2002). El lenguaje voluntario y de elección libre es la gramática en la que se traduce lo que buscan los clientes en los bancos: que se inscriban en proyectos. Así, los bancos construyen a sus clientes en partícipes de un intercambio comercial cuando penetran su intimidad y la traducen en proyectos y necesidades. Como es de advertirse, la transacción bancaria empieza a asumir otra intensidad social de la que se deriva de una descripción neutra. Esta pista lleva a Lazarus a continuar explorando la dimensión normativa en la relación bancaria. La observación se traslada a la gestión del dinero a través de las cuentas corrientes 
(capítulo 4) y la utilización del crédito y el ahorro (capítulo 5).

Los instrumentos bancarios confrontan una dimensión normativa. La exploración del empleo de las cuentas bancarias confirma esta interpretación. Las condiciones materiales y cognitivas de calculabilidad del dinero cambian con las cuentas en los bancos. La banca socializa a sus clientes en una forma desestructurante en el uso de las cuentas. Los medios de pago desmaterializados, los descubiertos autorizados y los eventuales créditos facilitan esta desestructuración. Este cambio, en relación con la gestión del dinero, abre un espacio de indeterminación normativo a través de las cuentas bancarias. ¿Quién debe controlar las cuentas bancarias? ¿El banco o los clientes? ¿Cuál es el límite de gastar más que los ingresos? Lazarus muestra que no hay respuesta rígida para esta pregunta: por ejemplo, se pasa de la autorización del descubierto a la prohibición de manera intempestiva. La normatividad en el uso de las cuentas es tan cierta como la variabilidad de reglas al respecto, es la conclusión de Lazarus.

La sociología, la antropología o la historia del crédito han trabajado densamente la dimensión moral de esta práctica. En L'épreuve... encontramos nuevos aportes a este campo. La tesis de Lazarus es: el crédito acordado por las instituciones financieras no ha transformado únicamente su aspecto técnico, también su aspecto moral. Su condena ha dejado lugar a su relativa banalización. El capítulo 5 es una sociohistoria de la pérdida de peso de la oposición moral entre el ahorro y el crédito, y la conversión de ambos en productos bancarios. El crédito se ha convertido en un instrumento que impulsa el consumo políticamente deseable en una economía de producción de masa. El crédito no es más el espejo - moral- invertido del ahorro. Esta transformación obedece fundamentalmente a que se erosionó la ética del ahorro y ha devenido menos sólida y dominante. La ética del crédito nunca logró constituirse en un sentido fuerte, sus detractores todavía son numerosos. ¿Significa que las personas se han tornado más frías y calculadoras, y toman decisiones monetarias sin acudir a referencias morales? Lazarus es determinante: las cuestiones morales relativas al uso del dinero son todavía centrales pero no remiten a consideraciones universales sino a dimensiones más locales, privadas y familiares.

El crédito a los particulares se ha expandido, es un instrumento para ampliar el consumo a la vez que un vector de socialización monetaria. La importancia social del crédito convive, sostiene Lazarus, con una impugnación secular sobre su uso. ¿Cómo se ha resuelto esta relativa contradicción? El capítulo 6 es un intento de responder esta pregunta a través del uso de un tipo de crédito específico: crédito revolving - renovable-. La apuesta de la autora es interesante. Analiza algunos de los instrumentos crediticios que han sido objeto de más impugnaciones, dado que se asocian con el sobreendeudamiento. Frente a esta hostilidad, los promotores de este tipo de crédito ofrecen un servicio que viene organizado a través de una región moral - Lazarus retoma el término de Robert Park-, que provee el marco para limar las tensiones normativas. Esta región moral limita la relación entre vendedores y compradores del crédito, establece un marco de suma discreción. Relaciones basadas en la distancia y el anonimato - adquisición vía telefónica-, interacciones en locales donde la despersonalización domina la transacción, distancia social entre vendedores y clientes o adquirientes son circunstancias que favorecen el mantenimiento de una región moral discreta que bloquea las tensiones normativas. Se trata de ofrecer un producto como otros, es decir, de desdramatizar el crédito.

Las relaciones bancarias necesitan de un buen cliente para constituirse en transacciones comerciales, y la construcción de 
esta figura se desarrolla a través de las pruebas que califican positivamente a los clientes frente a los bancos. En el capítulo 7 este concepto de prueba, que proviene de la sociología pragmática de Luc Boltanski y Laurent Thévenot, aparece con toda su utilidad analítica. Los ejes que sigue la autora son las pruebas evaluadas para otorgar un crédito, la autorización de un descubierto bancario y la apertura de una cuenta. Las evaluaciones para otorgar un crédito son de naturaleza variable, pero los elementos centrales a considerar son los que permiten comprobar la estabilidad — profesión, tipo de contrato, antigüedad,

214 dirección-como indicador de integración social. El contraste ocurre con el caso de Estados Unidos, donde el elemento central es la historia crediticia (Poon, 2009). Cuando los dossiers no pasan la evaluación informativa, la evaluación de la persona y la construcción de la confianza se tornan cruciales. Lazarus permite así contrarrestar la oposición entre especies de garantía - para retomar una noción de la sociología bourdesiana del crédito-y ver cómo coexisten. En efecto, para la autora no hay un reemplazo de evaluaciones subjetivas por objetivas sino la coexistencia de ambas en la relación bancaria, incluso en aquellas altamente tecnologizadas y burocratizadas. Finalmente se evalúan los proyectos y la capacidad de financiamiento.

El otorgamiento de descubiertos apunta a otras pruebas. En principio, los clientes son evaluados por la buena gestión de sus cuentas. El banco provee criterios a sus empleados sobre lo que se considera gastar bien el dinero. Lazarus observa que cuando los clientes son de origen popular la tendencia a esta evaluación es mayor. Por último está el análisis de la apertura de las cuentas, aspecto respecto del cual la autora encuentra muy clara la situación que quiere describir de las relaciones bancarias. Aunque según los informantes abrir una cuenta se concibe como una tarea meramente administrativa, al igual que en las prácticas anteriores la evaluación es intensa. En las entrevistas de admisión se plantean preguntas anodinas, pero se busca una coherencia en la historia de las personas y en la construcción de índices que muestren la seguridad y la calidad económica de los clientes.

Las pruebas que requieren reunirse para ser un buen cliente - seguridad, honestidad, rentabilidad- se complementan con una prueba suplementaria y que es la más valorada: la autonomía. La banca contemporánea necesita tener clientes que sean considerados autónomos. Esta calificación anima competencias técnicas - saber usar competentemente los servicios de los bancos- y morales -interiorizar las obligaciones de una banca que busca clientes responsables-. Éste es el cliente en el que los empleados de los bancos confían. El cliente autónomo garantiza que la relación bancaria se inscriba íntegramente en la ciudad mercantil (Boltanski y Thévenot, 1991) y que no busque desplegar argumentos del orden cívico o doméstico. Como todo orden normativo contradictorio, las relaciones bancarias generan sus propias crisis, recrudecidas por la importancia creciente que tiene en la vida de las personas lo que sucede en los bancos. El noveno capítulo es un intento de comprender cómo se despliegan estas crisis. Durante estos periodos, las transacciones con la banca devienen obsesivas y en un asunto de "vida o muerte" para los clientes. En estas circunstancias, la autonomía buscada en la relación bancaria deriva en su contrario: una total dependencia, y la relación de servicio se convierte en una atadura en la vida de los clientes. Las crisis se inician por cuestiones financieras que se complementan con un desacuerdo sobre la evaluación de la situación por parte de la banca y sus clientes. El espacio normativo contradictorio confiere a las reglas que impone la banca una 
legitimidad insuficiente. Por este motivo, los clientes cuentan con estrategias variables para salir de la crisis - evitar la relación con el banco, mentir, protestar o negociar-.

El recorrido por estos capítulos demuestra claramente que L'épreuve de l'argent... es una monografía ejemplar de las relaciones bancarias contemporáneas. Al considerar el encuentro de un cliente con su banco como un intenso proceso de evaluación de sí, de su modo de vida, de calcular y de pensar, este libro lleva a reposicionar la dimensión moral de la actividad económica en el corazón de las instituciones bancarias actuales. Con base en investigaciones como la de Lazarus, los especialistas en la sociología y la antropología de la economía no podemos más que seguir afirmando aquella idea de Mauss en la cual aseguraba que "sin una noción de valor no hay fenómenos económicos". Estos fenómenos no se oponen externamente a los órdenes morales sino que asoman como tales a través ellos. En relación con este punto, el trabajo de Lazarus también ilumina el antagonismo moral como proceso de lucha y diferenciación económica permanente. Su sociología moral permite pensar los reconocimientos éticos como poderes que posicionan mejor a los agentes en la competencia económica. ${ }^{1}$ En este sentido, contribuye a trazar una topografía de los antagonismos morales que atraviesan el mundo económico - no sólo en su periferia, sino en su centro-y que le dan su fisonomía.

\section{BIBLIOGRAFÍA}

Boltanski, Luc y Laurent Thévenot, 1991, De la justification. Les économies de la grandeur, Gallimard, París. y Éve Chiapello, 2002, El nuevo espíritu del capitalismo, Akal, Madrid.

Bourdieu, Pierre, Luc Boltanski y Jeanne-Claude Chamboredon, 1963, "La banque et sa clientèle : Éléments pour une sociologie du crédit", en Rapport du Centre de Sociologie Européenne, Centre de Sociologie Européenne, París.

Callon, Michel, 1986, "Algunos elementos para una sociología de la traducción: la domesticación de las vieiras y los pescadores de la bahía de St. Brieuc", en Juan Manuel Iranzo, Teresa González de la Fe y José Rubén Blanco (coords.), Sociología de la ciencia y la tecnología, Centro de Investigaciones Sociológicas, Madrid, pp. 259-282.

Carruthers, Bruce y Jeong-Chul Kim, 2011, "The Sociology of Finance", en Annual Review of Sociology, núm. 37, pp. 239-259.

\footnotetext{
${ }^{1}$ Con una perspectiva más próxima a la sociología de Bourdieu, arribamos a ideas similares de la vida económica por medio de la construcción del concepto de capital moral para comprender las dinámicas monetarias y financieras de las clases populares en el Gran Buenos Aires (Wilkis, 2010).
}

Lapavitzas, Costas, 2009, El capitalismo financiarizado. Expansión y crisis, Maida, Madrid. Maurer, Bill, 2012, "The Disunity of Finance: Alternative Practices to Western Finance", en Karin Knorr-Cetina y Alex Preda (eds.), Oxford Handbook of Sociology of Finance, Oxford.

Müller, Lúcia, 2009, “'Então, eu fui à luta!': repensando as representações e práticas econômicas de grupos populares a partir de uma trajetória de ascensão social", en Political Sociedade, vol. 8, núm. 15, pp. 145-171.

Ossandón, José (comp.), 2011, Destapando la caja negra. Sociología de los créditos de consumo en Chile, Universidad Diego Portales, Santiago.

Poon, Marta, 2009, "From New Deal Institutions to Capital Markets: Commercial Consumer Risk Scores and the Making of Subprime Mortgage Finance", en Accounting, Organizations and Society, núm. 34, pp. 654-674.

Villarreal, Magdalena, 2009, Mujeres, finanzas sociales y violencia económica en zonas marginadas de Guadalajara, Instituto Jalisciense de las Mujeres, Instituto Municipal de las Mujeres de Guadalajara, Guadalajara.

Wilkis, Ariel, 2010, "Capital moral et pratiques économiques dans la vie sociale des classes populaires de la banlieue de Buenos-Aires", tesis de doctorado, École des Hautes Études en Sciences Sociales, Universidad de Buenos Aires. 